\title{
openheart Non-hyperaemic pressure ratios to guide percutaneous coronary intervention
}

\author{
Michael Michail (D) , ${ }^{1,2}$ Udit Thakur, ${ }^{1}$ Ojas Mehta, ${ }^{1}$ John M Ramzy, ${ }^{1}$ \\ Andrea Comella, ${ }^{1}$ Abdul Rahman Ihdayhid, ${ }^{1}$ James D Cameron, ${ }^{1}$ \\ Stephen J Nicholls, ${ }^{1}$ Stephen P Hoole, ${ }^{3}$ Adam J Brown ${ }^{1}$
}

To cite: Michail M, Thakur U, Mehta 0, et al. Non-hyperaemic pressure ratios to guide percutaneous coronary intervention. Open Heart 2020;7:e001308. doi:10.1136/ openhrt-2020-001308

Received 6 April 2020 Revised 3 July 2020 Accepted 7 August 2020
Check for updates

\section{C) Author(s) (or their} employer(s)) 2020. Re-use permitted under CC BY-NC. No commercial re-use. See rights and permissions. Published by BMJ.

${ }^{1}$ Monash Cardiovascular Research Centre and MonashHeart, Monash University and Monash Health, Melbourne, Victoria, Australia

${ }^{2}$ Institute of Cardiovascular Science, University College London, London, United Kingdom

${ }^{3}$ Department of Interventional Cardiology, Papworth Hospital NHS Foundation Trust,

Cambridge, UK

\section{Correspondence to}

Dr Michael Michail; michael. michail@nhs.net

\section{ABSTRACT}

The use of fractional flow reserve (FFR) in guiding revascularisation improves patient outcomes and has been well-established in clinical guidelines. Despite this, the uptake of FFR has been limited, likely attributable to the perceived increase in procedural time and use of hyperaemic agents that can cause patient discomfort. This has led to the development of instantaneous wave-free ratio (iFR), an alternative non-hyperaemic pressure ratio (NHPR). Since its inception, the use of iFR has been supported by an increasing body of evidence and is now guideline recommended. More recently, other commercially available NHPRs including diastolic hyperaemia-free ratio and resting full-cycle ratio have emerged. Studies have demonstrated that these indices, in addition to mean distal coronary artery pressure to mean aortic pressure ratio, are mathematically analogous (with specific nuances) to iFR. Additionally, there is increasing data demonstrating the equivalent diagnostic performance of alternative NHPRs in comparison with iFR and FFR. These NHPRs are now integral within most current pressure wire systems and are commonly available in the catheter laboratory. It is therefore key to understand the fundamental differences and evidence for NHPRs to guide appropriate clinical decision-making.

\section{INTRODUCTION}

Ischaemic heart disease remains a leading cause of morbidity and mortality. ${ }^{1}$ Myocardial revascularisation is an important treatment modality for patients with obstructive coronary artery disease (CAD), with use of invasive and non-invasive functional modalities improving the selection of patients that would most likely benefit. The use of invasive pressure-based functional assessment has now permitted identification of lesionlevel ischaemia to better guide revascularisation strategies. Fractional flow reserve (FFR) is the most established of these tools and permits the measurements of pressure gradients across a lesion. FFR measurements are acquired during hyperaemia to minimise the influence of the coronary microcirculation.
Despite a robust body of evidence supporting its use, clinical uptake of FFR remains low and highly variable between healthcare systems. ${ }^{2}$ Reasons for poor uptake include the perceived additional procedural cost and time, as well as the discomfort to patients with administration of hyperaemic agents. ${ }^{3}$ This has led to the development of alternative invasive non-hyperaemic pressure ratios (NHPR) that may improve the uptake of physiologically-guided revascularisation.

The instantaneous wave-free ratio (iFR; Philips Volcano Corporation, San Diego, California, USA) is a diastolic-only index and was the first specific NHPR to become commercially available (figure 1). While there was some initial scepticism that an NHPR could perform as well as FFR, ${ }^{4}$ two large randomised controlled trials have demonstrated its non-inferiority to FFR in the assessment of intermediate lesions. ${ }^{35} \mathrm{An}$ increasing body of evidence has supported its clinical utility and iFR was recently incorporated into the European guidelines on myocardial revascularisation for use in the functional assessment of patients with stable angina (class I recommendation, level of evidence A). ${ }^{6}$ Following the arrival of iFR to market, other NHPRs have since been developed by competing companies and are now commercially available (figure 2) ${ }^{78}$ However, there are fundamental differences between each of these indices, relating to the sampling period of the cardiac cycle from which they are derived and data justifying their use, which has largely been provided by demonstrating non-inferiority and equivalence to iFR. This review aims to assist cardiologists in understanding the NHPRs available and the data supporting their use to guide appropriate clinical decision-making. This review also describes the methodological considerations and clinical interpretation in their use in different lesion and patient subsets. 


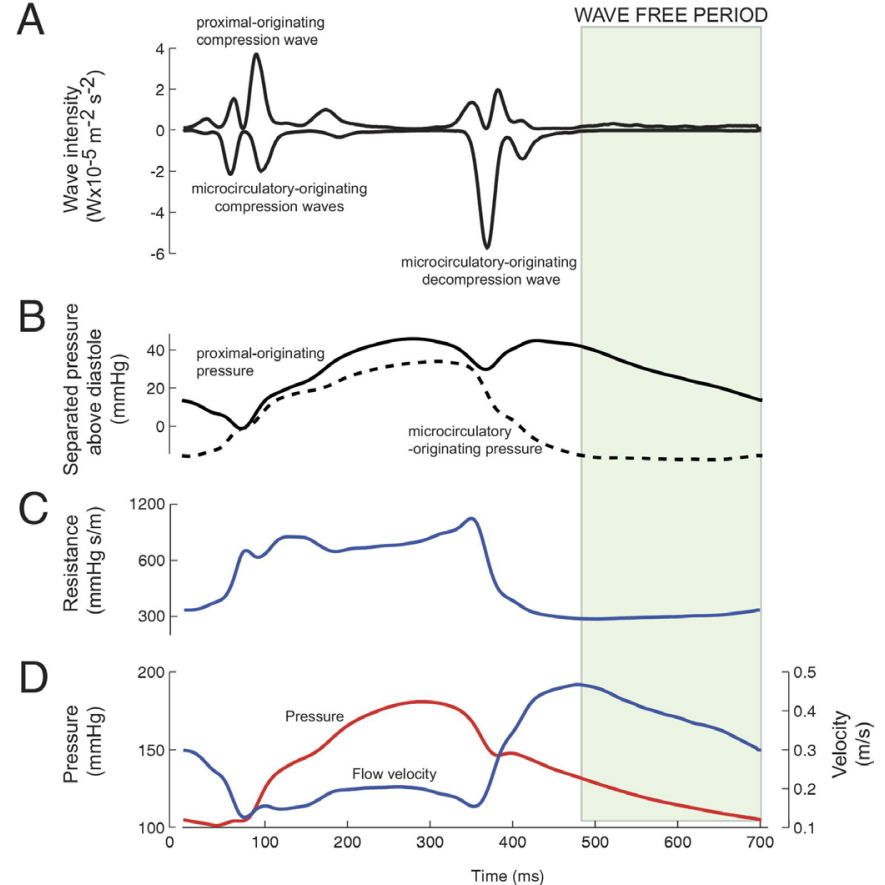

Figure 1 The physiological derivation of the wave-free period (WFP). Wave intensity analysis (A) demonstrates a WFP (green shaded area), a segment in the cardiac cycle when there is minimal microcirculatory originating pressure (B), minimal and constant coronary resistance (C) and therefore, coronary flow velocity (blue) and pressure (red) are both linearly related (D). Reproduced from Sen et al. ${ }^{21}$

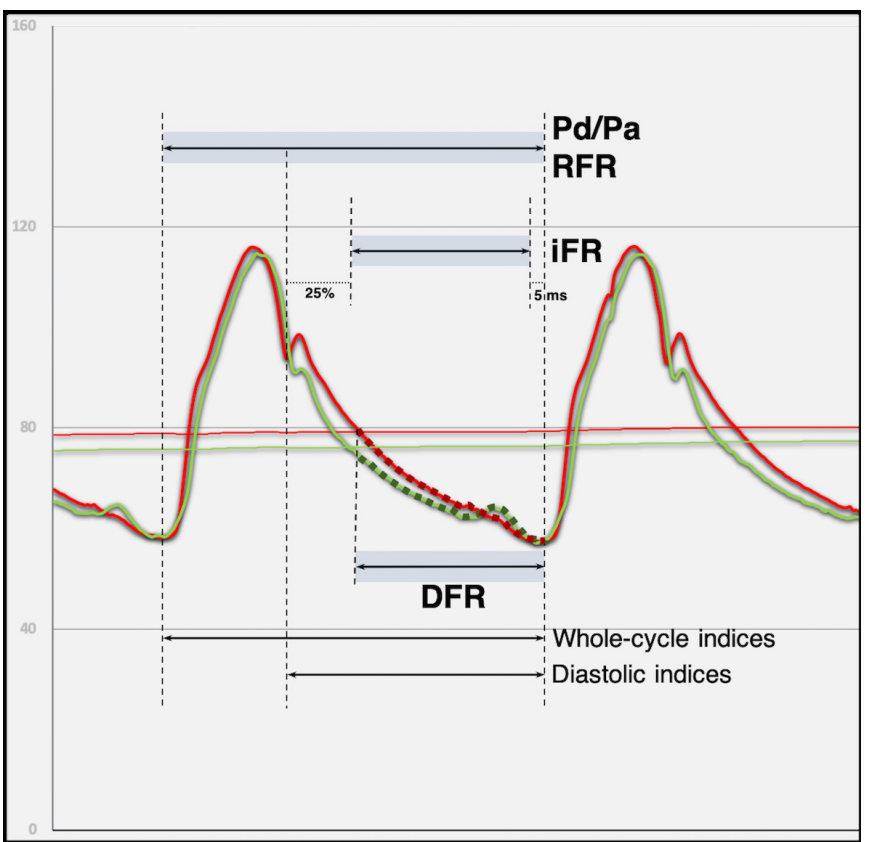

Figure 2 Schematic representation of the commonly available non-hyperaemic pressure ratios and the periods of the cardiac cycle from which they are calculated. DFR, diastolic hyperaemia-free ratio; iFR, instantaneous wave-free ratio; $\mathrm{Pd} / \mathrm{Pa}$, ratio of mean distal coronary artery pressure to mean aortic pressure in the resting state; RFR, resting fullcycle ratio.

\section{PHYSIOLOGICAL BASIS OF RESTING PRESSURE-BASED} INDICES

FFR is an invasively determined index, derived as a method for assessing the functional impact of coronary stenosis. It is defined as the maximal blood flow to the myocardium in the presence of a stenosis in the supplying coronary artery, divided by the theoretical normal maximal flow in the same distribution. ${ }^{9}$ This can be calculated by measuring the ratio of the mean distal coronary artery pressure ( $\mathrm{Pd}$; distal to the stenosis) to the mean aortic pressure $(\mathrm{Pa})$ during maximal microvascular vasodilatation. Maximal vasodilatation using hyperaemic agents minimises and maintains constant microcirculatory resistance. During these conditions, pressure is proportional to coronary flow-thus allowing the measurement of pressure gradient across a lesion without being confounded by pressure changes in the distal microcirculatory bed. FFR was brought into clinical practice after its validation by Pijls and colleagues ${ }^{9}$ and has been robustly validated and tested in the subsequent two decades. ${ }^{10-16}$ Today it is considered the 'gold standard' and is a class IA recommendation in revascularisation guidelines. ${ }^{6}$

\section{Rise of diastolic non-hyperaemic indices-wave intensity analysis and the concept of iFR}

Coronary microvascular resistance fluctuates in a phasic pattern, due to the variable interaction between the myocardium and microvasculature, with the latter being compressed and decompressed during the cardiac cycle. ${ }^{17} 18$ Study into the relationship between coronary pressure and flow led to the identification of a 'wave-free period' (WFP) - a specific period during diastole that is free from the effects of forward and backward wave energies. This WFP permitted the measurement of coronary pressure during a period where microcirculatory resistance is constant-and not necessarily minimal-as was previously considered necessary. ${ }^{19-21}$ Physiologically, this mimics the constant microcirculatory resistance induced by adenosine during hyperaemic state whereby measured pressure is proportional to flow. Application of these principles paved an opportunity for a hyperaemia-free index and the subsequent development of iFR.

\section{iFR and other NHPRs}

A recent post-hoc analysis compared iFR against other defined resting indices using raw data from pressure waveforms, including diastolic and whole-cycle indices. ${ }^{22}$ Indices compared included diastolic pressure ratio (mean $\mathrm{Pd} / \mathrm{Pa}$ over the entire diastolic period), ratio of mean $\mathrm{Pd}$ to mean $\mathrm{Pa}(\mathrm{Pd} / \mathrm{Pa})$ and $\mathrm{Pd} / \mathrm{Pa}{ }_{\text {min }}$ (defined as the minimum value of the filtered point by point ratio of $\mathrm{Pd}$ and $\mathrm{Pa}$ for a single heart cycle). The investigators found the Spearman's correlation coefficient for all diastolic indices against iFR to be $>0.99$, leading the authors to conclude that all diastolic resting indices were numerically identical irrespectiveof restriction to the WFP. Similarly, the correlations between resting $\mathrm{Pd} / \mathrm{Pa}$ and $\mathrm{Pd}$ / $\mathrm{Pa}_{\text {min }}$ were 0.95 and 0.97 , respectively. 
Table 1 Currently available non-hyperaemic pressure ratios (NHPRs)

\begin{tabular}{|c|c|c|c|c|c|}
\hline NHPR & Calculation & $\begin{array}{l}\text { Period of } \\
\text { the cardiac } \\
\text { cycle }\end{array}$ & Manufacturer & Threshold & Summary of evidence \\
\hline $\begin{array}{l}\text { Instantaneous wave- } \\
\text { free ratio (iFR) }\end{array}$ & $\begin{array}{l}\mathrm{Pd} / \mathrm{Pa} \text { calculated during the WFP } \\
\text { within diastole. }\end{array}$ & WFP in diastole & Philips Healthcare & $\leq 0.89$ & $\begin{array}{l}\text { Validated by randomised prospective clinical } \\
\text { trials: DEFINE-FLAIR and SWEDEHEART. }{ }^{35} \text { iFR } \\
\text { non-inferior to FFR for MACE at } 1 \text { year. }\end{array}$ \\
\hline $\begin{array}{l}\text { Resting full-cycle ratio } \\
\text { (RFR) }\end{array}$ & $\begin{array}{l}\text { The lowest } \mathrm{Pd} / \mathrm{Pa} \text { over the entire } \\
\text { cardiac cycle. Mean of } 4-5 \\
\text { consecutive cycles. }\end{array}$ & Whole cycle & Abbott & $\leq 0.89$ & $\begin{array}{l}\text { VALIDATE RFR and RE-VALIDATE RFR both show } \\
\text { diagnostic equivalence between RFR and iFR. } \\
{ }^{73} \text { RFR correlates as highly with FFR as do other } \\
\text { NHPR's. }\end{array}$ \\
\hline $\begin{array}{l}\text { Diastolic hyperemia- } \\
\text { free ratio (DFR) }\end{array}$ & $\begin{array}{l}\text { Average } \mathrm{Pd} / \mathrm{Pa} \text { over the } \\
\text { approximated* diastolic period } \\
\text { averaged over five consecutive } \\
\text { cardiac cycles. }\end{array}$ & Diastole & Boston Scientific & $\leq 0.89$ & $\begin{array}{l}\text { DFR is diagnostically equivalent to iFR in } \\
\text { multiple validation studies. }{ }^{82} \text { DFR correlates as } \\
\text { highly with FFR as do other NHPR's. }\end{array}$ \\
\hline Resting $\mathrm{Pd} / \mathrm{Pa}$ & $\begin{array}{l}\text { Resting } \mathrm{Pd} / \mathrm{Pa} \text { averaged over the } \\
\text { entire cardiac cycle. }\end{array}$ & Whole cycle & $\begin{array}{l}\text { Not proprietary } \\
\text { technology }\end{array}$ & $\leq 0.91$ & $\begin{array}{l}\text { Resting } \mathrm{Pd} / \mathrm{Pa} \text { provides excellent agreement } \\
\text { with iFR and FFR. Resting } \mathrm{Pd} / \mathrm{Pa} \text { has slightly } \\
\text { lower sensitivity to stenosis severity than iFR. }\end{array}$ \\
\hline
\end{tabular}

*Diastole approximated as negatively sloped segment of tracing where instantaneous $\mathrm{Pa}$ falls below mean Pa.

FFR, fractional flow reserve; $\mathrm{Pd} / \mathrm{Pa}$, ratio of mean distal coronary artery pressure to mean aortic pressure in the resting state; WFP, wave-free period.

New NHPRs which exploit these correlations have since become commercially available (table 1 ). This includes diastolic hyperaemia-free ratio (DFR; Boston Scientific, Natick, Massachusetts, USA) and resting full-cycle ratio (RFR, Abbott Vascular, Santa Clara, California, USA). DFR uses the mean $\mathrm{Pd} / \mathrm{Pa}$ calculated over the period in diastole defined as that during which arterial pressure is negatively sloped and below the mean arterial pressure. This method allows approximation of diastole without the need to identify the dichrotic notch, which can be technically challenging in damped traces. ${ }^{83}$ In contrast, RFR is derived from 4 to 5 consecutive cardiac cycles by calculating the minimum $\mathrm{Pd} / \mathrm{Pa}$ within the cardiac cycle, after smoothing of the instantaneous $\mathrm{Pd} / \mathrm{Pa}$ trace. ${ }^{7}$ In the RFR validation study, this point was located within diastole in $88 \%$ of cases. ${ }^{7}$

There are now several large studies which demonstrate that the strong correlations between iFR and other NHPRs present numerically identical results and therefore a widely shared view is that a class effect should be considered. $^{82} 24$ However, it merits consideration that apart from iFR, other NHPRs have not been scrutinised in prospective trials.

\section{METHODOLOGICAL CONSIDERATIONS}

There are some practical considerations that are important to account for when using NHPRs. While modern pressure wires provide high fidelity measurements, pressure drift can be a source of error which may inadvertently result in the misclassification of lesions. Since FFR mandates the use of hyperaemic agents, transtenotic pressure gradients are greater than those measured using NHPRs. This means that small pressure drifts are likely to have a greater impact on NHPRs than they would on FFR. Thus, stringent measures of all NHPRs should be taken in order to minimise drift and lesion misclassification. This includes adherence to the standardised practice, for example, ensuring no guide catheter dampening, no blood leaking (causing pressure loss) around the introducer and no contrast medium within the guiding catheter.

Another potential consideration in using NHPR is heart rate (HR) during pressure wire assessment. Increasing the HR likely affects all indices (usually by lowering the readings) which may result in the misclassifications of lesions. ${ }^{25}$ The period in the cardiac cycle from which NHPRs are derived may be additionally relevant in tachycardic patients, as it may adversely affect diastolic-only indices to a greater extent due to the relative shortening of diastole.

Notwithstanding all the above considerations, there are error margins with all invasive pressure indices, which may result in the reclassification of lesions. Evidence has demonstrated a risk continuum where lower FFR values are associated with higher rates of clinical events. ${ }^{26}$ Therefore, as with hyperaemic pressure indices, NHPRs should not simply be treated as dichotomous tools, but rather clinical judgement should be exercised in their interpretation.

\section{CURRENT EVIDENCE FOR THE USE OF AVAILABLE TECHNOLOGIES \\ Instantaneous wave-free ratio}

The validation of iFR originated from multiple studies demonstrating concordance between iFR and FFR for the assessment of intermediate severity coronary artery stenosis. An iFR cut-off $\leq 0.89$ was shown to best predict FFR $\leq 0.80 .{ }^{27-30}$ However, the VERIFY II trial did challenge the correlation of iFR with FFR $(r=0.73, p=0.001)$ finding a misclassification rate of $21 \%$ in lesions using 


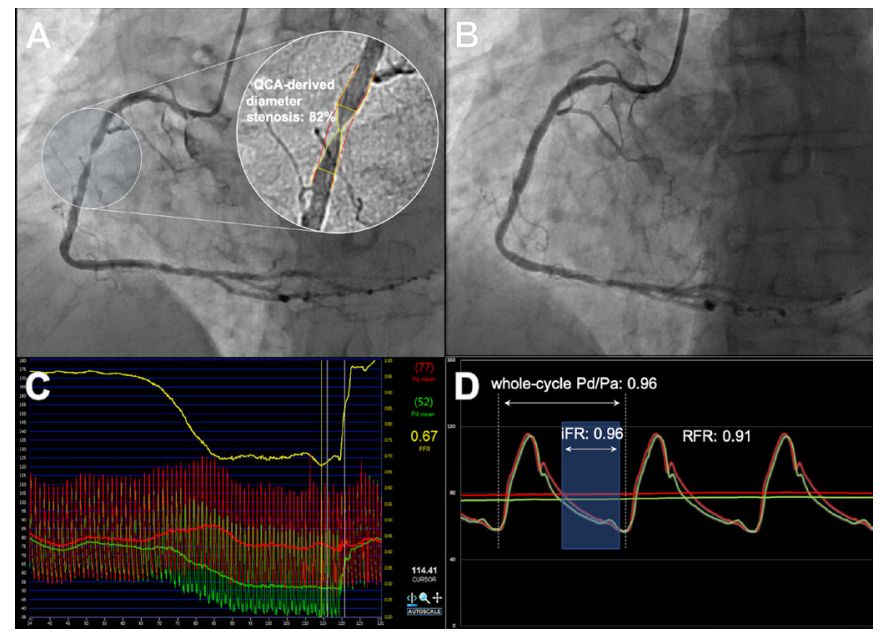

Figure 3 Representative case of significant discordance between hyperaemic and non-hyperaemic pressure ratios (NHPRs). Pressure wire study was performed in a severe stenosis in the right coronary artery $(A)$ which was subsequently treated with $3.5 \mathrm{~mm} \times 12 \mathrm{~mm}$ everolimuseluting stent (B). There was a notably positive fractional flow reserve at $0.67(\mathrm{C})$ with negative NHPRs (D) including resting full-cycle ratio (RFR; 0.91), whole-cycle $\mathrm{Pd} / \mathrm{Pa}(0.96)$ and instantaneous wave-free ratio (iFR; 0.96). Reproduced from Michail et $\mathrm{a} /{ }^{37}$. $\mathrm{Pd} / \mathrm{Pa}$, ratio of mean distal coronary artery pressure to mean aortic pressure in the resting state.

iFR compared against FFR (area under the receiver operating characteristic curve [ROC AUC] 0.85); warranting studies to assess clinical outcomes associated with iFR. ${ }^{31}$ Consequently, non-inferiority of iFR compared with FFR was demonstrated in two large prospective randomised trials: DEFINE-FLAIR and SWEDEHEART. ${ }^{35}$

DEFINE-FLAIR randomly allocated participants in a 1:1 ratio to undergo either iFR-guided or FFR-guided revascularisation. The study included both stable and non-culprit vessels in patients presenting with acute coronary syndromes (ACS). The primary endpoint of major adverse cardiac events at 1 year was not different between the two groups $(6.8 \%$ vs $7.0 \%, \mathrm{HR}=0.95, \mathrm{p}=0.78)$. Expectedly, the procedural time was significantly shorter in the iFR group ( 40.5 vs $45.0 \mathrm{~min}, \mathrm{p}<0.001$ ) and the number of patients reporting adverse procedural symptoms was significantly higher in the FFR group secondary to vasodilator use $(3.1 \%$ vs $30.8 \%, \mathrm{p}<0.001)$. The SWEDEHEART trial randomised a large cohort to iFR versus FFR guided revascularisation with similar results at 1-year follow-up. The primary endpoint of major adverse cardiovascular events (MACE) occurred in $6.7 \%$ of iFR-guided versus $6.1 \%$ in FFR-guided percutaneous coronary intervention (PCI; HR=1.12, p=0.53). Adverse procedural symptoms were again higher in the FFR cohort $(3.0 \%$ vs $68.3 \%$, $\mathrm{p}<0.001)$. A subgroup analysis from the DEFINE-FLAIR trial explored the risk of left anteriordescending artery (LAD) lesion deferral based on iFR. ${ }^{32}$ The results from this substudy suggested iFR-guided deferral in the LAD led to a lower MACE rate at 1-year follow-up compared with FFR (2.44\% vs $5.26 \%$, HR 0.46, $\mathrm{p}=0.04)$. This composite endpoint was driven by statistically higher unplanned revascularisation and numerically higher myocardial infarction related to the LAD in the FFR arm. However, this post-hoc analysis was underpowered to validate differences among subgroups. This study also did not individually explore the outcomes of the circumflex and right coronary artery (RCA). The two studies were limited by low-risk patient demographics; with an average age below 70 years and the majority of patients undergoing intervention for stable CAD. Furthermore, both RCT's were powered only to evaluate non-inferiority between the modalities as approximately $80 \%$ of iFR and FFR results are concordant.

There is no long-term randomised data available on iFR outcomes at this stage, with the above trials being limited by a follow-up period of 1 year. Nonetheless, the 2018 European Society of Cardiology guidelines on myocardial revascularisation have incorporated a level $1 \mathrm{~A}$ recommendation for the use of iFR in the haemodynamic assessment of intermediate-grade stenosis. ${ }^{6}$

\section{Resting full-cycle ratio}

RFR uses the maximal relative pressure difference over the entire cardiac cycle and is not limited to diastole. RFR was recently shown to be diagnostically equivalent to iFR in the VALIDATE-RFR study. ${ }^{7}$ This retrospective study derived an optimal cut-off $\leq 0.89$ using receiver operator curve analysis with the clinically accepted FFR cut-off $\leq 0.80$. Using this cut-off, RFR correlated very highly with iFR $\left(\mathrm{R}^{2}=0.985, \mathrm{p}<0.001\right)$ with high diagnostic equivalence (mean difference $-0.002, \mathrm{p}=0.03$ ). Both RFR and iFR moderately correlated with FFR $\left(\mathrm{R}^{2}=0.557\right.$ vs 0.540 with $\mathrm{p}<0.001$ for both correlations). Subsequently, RE-VALIDATE RFR provided prospective analysis of RFR compared with iFR, showing similar levels of equivalence. $^{33}$

While coronary perfusion is predominantly diastolic, it is recognised that the RCA perfuses in systole to a greater degree than in the left coronary artery. ${ }^{34} 35$ This may be attributable to the thinner-walled right ventricle which results in less systolic compression compared with the left ventricle. In addition, compared with the left coronary artery, the RCA has a smaller 'diastolic suction wave' which is responsible for accelerating diastolic coronary blood flow. In VALIDATE-RFR it was observed that the lowest $\mathrm{Pd} / \mathrm{Pa}$ ratio was outside of the diastolic period in $12.2 \%$ of patients. ${ }^{7}$ This observation was greater in the RCA than the left coronary system; with the sensitivity of both RFR and iFR notably lower in the RCA. A reduced sensitivity of iFR compared with FFR has previously been observed in the RCA (figure 3). ${ }^{36} 37$ This raises the important question as to whether NHPRs and in particular diastolic-only indices are physiologically less-suited for assessment of lesions in the RCA. Further research is warranted to evaluate if there is a benefit to using wholecycle NHPRs such as RFR or $\mathrm{Pd} / \mathrm{Pa}$ in the assessment of RCA lesions. 


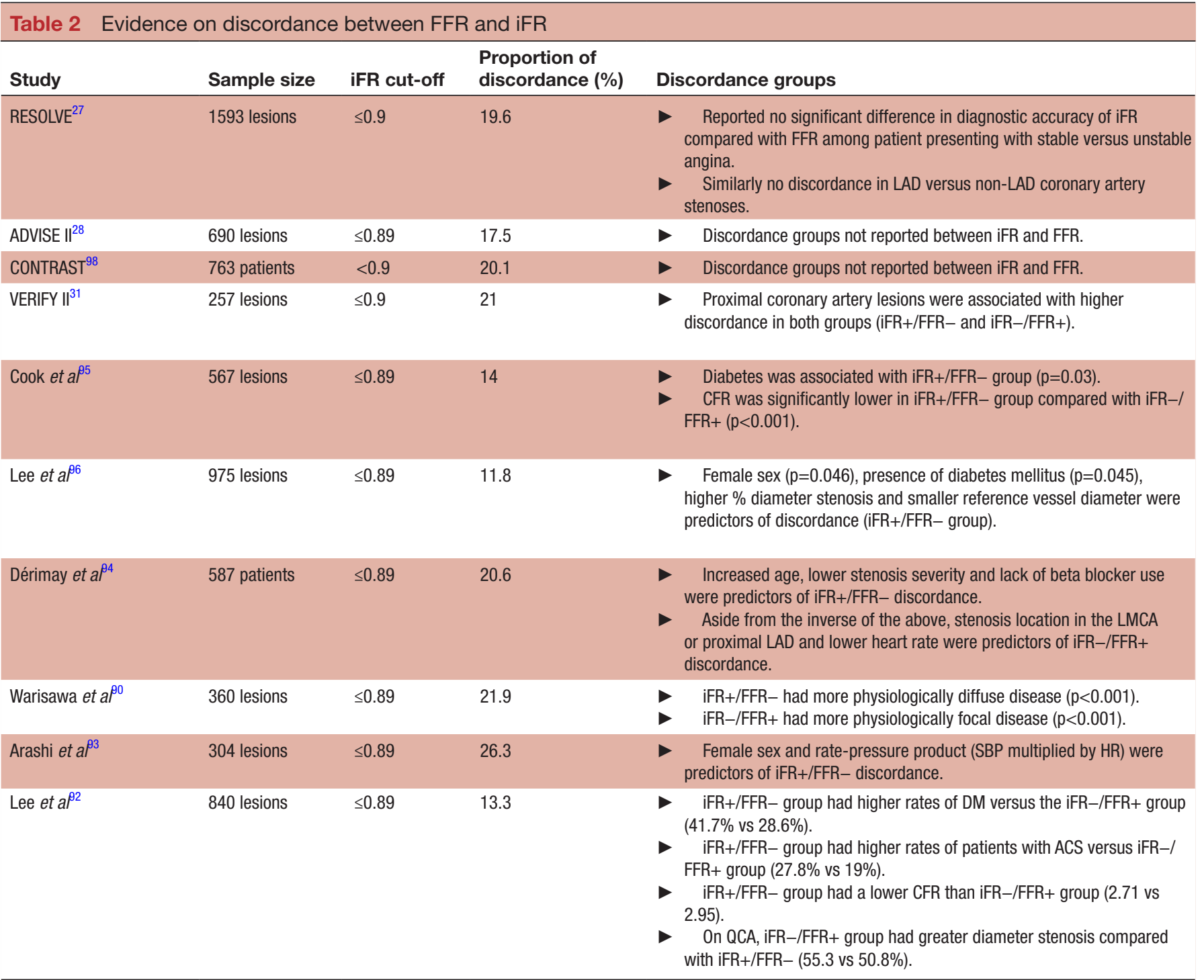

CFR, coronary flow reserve; FFR, fractional flow reserve; HR, heart rate; iFR, instantaneous wave-free ratio; LAD, left anterior descending artery; LMCA, left main coronary artery; QCA, quantitative coronary angiography; SBP, systolic blood pressure.

\section{Diastolic hyperaemia-free ratio}

DFR is a diastolic index that uses average $\mathrm{Pd} / \mathrm{Pa}$ within an approximated diastole over five consecutive cycles. In a post-hoc analysis of 833 patients from the VERIFY II and CONTRAST studies, DFR has been shown to be numerically equivalent to iFR across 893 lesions (combined difference with iFR for DFR $-0.006 \pm 0.011, \mathrm{R}^{2}=0.993$, accuracy $97.6 \%) .{ }^{8}$ Another study similarly demonstrated significantly high correlations between both DFR and RFR with iFR. ${ }^{24}$ In this study, deferred vessels with retrospective iFR, DFR and RFR $\leq 0.89$ all showed significantly higher rates (iFR, $9.5 \%$ vs 2.1 ; DFR, $7.5 \%$ vs $2.2 \%$; RFR $6.4 \%$ vs $2.2 \%$; $\mathrm{p}<0.001$ for all) of the composite endpoint (cardiac death and target vessel failure).

\section{Resting whole-cycle Pd/Pa}

In view of the recent interest in NHPRs, there has been a resurgence of interest in the use of resting $\mathrm{Pd} / \mathrm{Pa}$ as it is not vendor-specific, is widely available and has been shown to strongly correlate with FFR. The RESOLVE study initially showed both iFR and resting Pd/Pa (using the accepted cutoff value of $\leq 0.91$ ) to have an overall accuracy of approximately $80 \%$ using FFR as the gold standard. ${ }^{27}$ The diagnostic accuracy of resting $\mathrm{Pd} / \mathrm{Pa}$ compared with FFR was further confirmed on meta-analysis. ${ }^{38}$ Another study has shown resting whole cycle $\mathrm{Pd} / \mathrm{Pa}$ to correlate highly with iFR $(r=0.970, p<0.001)$ and with increases in anatomic and haemodynamic severity. ${ }^{39}$ The authors demonstrated that patients with resting $\mathrm{Pd} / \mathrm{Pa} \leq 0.91$ had significantly higher rates of 2-year MACE (8.7\% vs 1.5\%, $\mathrm{p}=0.003)$. However, iFR appears to be more sensitive to the differences in stenosis severity. ${ }^{29}$ While resting whole-cycle $\mathrm{Pd} / \mathrm{Pa}$ has excellent agreement with iFR, its overall strength lies in its universal availability independent of specific vendors.

\section{SPECIAL PATIENT AND LESION SUBGROUPS Serial lesions}

In the setting of serial lesions, the accurate physiological assessment of each individual stenosis is challenging 
due to haemodynamic interdependence. ${ }^{40}$ Each lesion increases the total vessel resistance with a consequent reduction in flow. Furthermore, each stenosis can lead to a change in local flow conditions by causing laminar flow to become turbulent, which in turn further reduces the pressure at that point. It is suggested that hyperaemia augments these altered flow conditions by increasing the pressure-velocity gradient across each lesion. ${ }^{41}$ In contrast, at rest flow is maintained at a constant and the interplay between stenoses is lessened. As such, it has been proposed that NHPRs may be less prone to error than hyperaemic indices in the evaluation of serial stenoses and diffuse disease. ${ }^{42}$

The utility of iFR in the setting of serial lesions was demonstrated in a study of 32 coronary arteries that were interrogated using an automated iFR pullback. Virtual stenting was performed to the areas of high iFR intensity loss and an expected post-PCI iFR calculated. There was a small mean difference and strong correlation between the expected and observed post-PCI iFR $(r=0.97, \mathrm{p}<0.001){ }^{43}$ The ability of iFR pullback to reliably predict post-PCI physiology was also demonstrated in the primary results of the international multicentre iFR GRADIENT registry. ${ }^{44}$ Among the 134 vessels with tandem or diffuse CAD tested, the mean difference between the predicted and actual post-PCI iFR values was $0.011 \pm 0.004$ with a strong correlation $(r=0.73, p<0.001)$. Additionally, the ability of the iFR pullback to detect the individual contribution of each stenosis to the distal iFR resulted in a change in PCI strategy in $31 \%$ of vessels (compared with angiographybased decision making). ${ }^{44}$ The discrepancy between angiographically and physiologically defined targets for PCI were also highlighted in the results of the recently published DEFINE-PCI trial. ${ }^{45}$ Investigators in this study performed blinded iFR following PCI procedures that were deemed angiographically successful and found that one quarter of patients had residual ischaemia as defined by an $\mathrm{iFR} \leq 0.89$. Given the association of adverse outcomes with post-PCI residual ischaemia ${ }^{46}$ these findings signal the need for increase in physiologically-guided revascularisation. The upcoming DEFINE GPS study will aim to identify whether intervening on focal lesions identified by iFR pullback as responsible for residual ischaemia post-PCI reduces future adverse outcomes. Although the physiological principles relating to serial lesion assessment can potentially be extended to other NHPRs given their close correlations with iFR, there is currently no data to directly support this approach at present. The perceived advantages of using NHPRs in this setting has led to the commercialisation of 'iFR Scout' which provides the user with a pullback profile of the vessel to enable informed decision-making.

\section{Left main coronary artery}

Despite the well-recognised visual-functional mismatch between angiography and FFR in left main coronary artery (LMCA) lesions, ${ }^{47}$ these patients have often been excluded from the large physiological validation trials. ${ }^{3}{ }^{36}$
While long-term data suggest that deferring revascularisation of LMCA lesions on the basis of FFR is safe, ${ }^{48}$ this data are not available for iFR. Furthermore, discordance between iFR and FFR has been shown to be greatest in LMCA and proximal LAD lesions. ${ }^{49}$ A recent study examining the correlation between iFR and FFR in 91 angiographically intermediate LMCA stenoses found a significant correlation $(\mathrm{AUC}=0.84 ; \mathrm{p}<0.001)$ with classification agreement in $81 \%$ of cases. ${ }^{50}$ The iLITRO study which is estimated for completion in 2025 will aim to assess the concordance of FFR and iFR in LMCA lesions as well as to compare clinical outcomes between patients who have FFR-guided and iFR-guided treatment. Given the high incidence of downstream disease acting as serial stenoses, proponents of NHPR have suggested that LMCA lesions may best be assessed with NHPRs although outcome data for their use in this setting is required.

\section{Acute coronary syndromes}

The use of invasive physiological assessment is less established in patients presenting with ACS. ${ }^{51}$ Up to half of patients presenting with ST-elevation myocardial infarction are identified to have angiographically significant multi-vessel disease ${ }^{52}{ }^{53}$ highlighting the potential role of intracoronary physiology to enhance the evaluation and treatment of non-culprit lesions. Although there are concerns regarding a blunted hyperaemic response to adenosine following an acute myocardial infarction, ${ }^{54}$ the assessment of non-culprit ACS lesions with FFR has been shown to be reliable when assessed during the index procedure. ${ }^{55}$ Several randomised trials have also demonstrated that a strategy of FFR-guided revascularisation of non-culprit lesions in ACS significantly improves clinical outcomes compared with only treatment of the infarct-related artery. ${ }^{5758}$

In non-culprit ACS lesions, conflicting studies exist on the validity of NHPR. Choi et al found iFR values were similar in non-culprit ACS lesions compared with patients with stable CAD and similar stenosis severity. ${ }^{59}$ More recently, several comprehensive physiological studies have demonstrated that resting coronary flow in non-culprit ACS lesions is significantly higher than patients with stable CAD ${ }^{6061}$ This may be due to localised adenosine release in response to myocardial ischaemia, which results in a partial hyperaemic response. ${ }^{62}$ This may have important implications on the accuracy of NHPR in patients with ACS, as an increase in resting flow could potentially exaggerate the pressure loss across a lesion, overestimating its functional significance. Consequently, several studies have observed a 0.01-0.02 increase in iFR from the acute event to follow-up, ${ }^{54} 63$ highlighting the need for caution in interpreting iFR in the setting of large myocardial infarctions or values around the diagnostic threshold $(\leq 0.89)$.

A subanalysis of the DEFINE-FLAIR and iFRSWEDEHEART trials demonstrated that while overall outcomes between FFR and iFR were comparable, deferral with FFR in the ACS subgroup associated with a 
higher rate of clinical events compared with FFR deferral in stable CAD. ${ }^{64}$ In contrast, deferral with iFR yielded similar outcomes regardless of clinical presentation. ${ }^{64}$ The limitations of subgroup analysis prevent drawing definitive conclusions on the utility of one physiological tool over the other. The ongoing prospective, multicentre iFR Guided Multi-Vessel Revascularization During Percutaneous Coronary Intervention for Acute Myocardial Infarction trial will provide further insight into the clinical value of iFR guided revascularisation in non-culprit lesions of patients with acute STEMI.

\section{Aortic stenosis}

The use of pressure-based invasive indices in patients with severe aortic stenosis (AS) is an evolving field. Between $25 \%$ and $50 \%$ of patients with severe AS have coexisting $\mathrm{CAD}$ and while transcatheter aortic valve replacement (TAVR) has become an increasingly common treatment modality, the management of concomitant CAD remains controversial. A recent pooled analysis demonstrated that patients undergoing TAVR with higher residual SYNTAX (Synergy Between Percutaneous Coronary Intervention With Taxus and Cardiac Surgery) score were at risk of greater subsequent mortality. ${ }^{65}$ The importance of correctly identifying ischaemia-inducing lesions in such patients prompted the recent exploration of pressurebased indices in these cohorts. While the feasibility of both FFR and iFR has been demonstrated in such patients, there are concerns that the altered ventriculoaortic physiology distorts their accuracy. ${ }^{66}$ For example, the greater oxygen demands of hypertrophied ventricles in severe AS induces partial microcirculatory vasodilatation that increases resting coronary blood flow. ${ }^{67}$ Additionally, there is submaximal drug-induced hyperaemic response, potentially leading to underestimation of FFR significance. ${ }^{67-69}$ This latter point has led to speculation on the potential advantages of NHPR in severe AS, supported by clinicians' reluctance to use hyperaemic agents in such patients.

The feasibility and accuracy of using iFR in patients with severe AS has been demonstrated in several studies. ${ }^{70-72}$ The data suggest that a lower iFR cut-off ( 0.82 or 0.83 ) is better predictive of ischaemia-provoking lesions compared with that validated in patients with no AS. ${ }^{70} 72$ This is likely explained by the greater resting blood flow due to the larger myocardial mass and partial microcirculatory vasodilatation which would produce greater transstenotic pressure gradients. This would therefore result in the lower iFR values for the same lesion if it existed in a patient with non-AS. In contrast, FFR values are likely higher and underestimate the true ischaemic burden induced by lesions given the submaximal hyperaemia.

Several studies have demonstrated discrepancies in FFR and iFR values measured in the same lesion immediately before and after TAVR, ${ }^{67} 707173$ thus questioning the accuracy of the index reading. In one study of 66 patients, while mean iFR remained unchanged following TAVR there were notable variations within the individual
iFR values, prompting the authors to advise caution over its use. Another recent study measuring invasive pressure and flow also demonstrated unchanged mean iFR following TAVR. Conversely, mean FFR decreased from 0.87 to 0.85 . This was explained by an observed increase in systolic flow following TAVR (thus affecting whole-cycle indices), with no appreciable change in diastolic flow immediately after TAVR and thus no change in iFR. ${ }^{71}$ The remainder of the NHPRs have not been assessed in this context. There may be perceivable benefits to diastoliconly rather than whole-cycle indices in this context given the largely variable systolic physiology immediately before and after valve deployment.

The validity and role of pressure-based functional assessment of coronary stenosis in patients with severe AS continues to be investigated and two large randomised trials (NOTION-3 (NCT03058627) and FAITAVI (NCT03360591)) are currently underway to investigate the outcomes of upstream FFR-guided PCI in patients undergoing TAVR.

\section{Myocardial bridging}

Myocardial bridging (MB) has traditionally been considered a benign condition with preserved coronary perfusion in diastole. However, its associations with ACS ${ }^{74}$ Takotsubo's cardiomyopathy ${ }^{75}$ and malignant arrhythmias $^{76}$ has highlighted attention on physiological assessment. Unlike coronary atherosclerosis, MB is a dynamic lesion that changes degree of luminal stenosis throughout the cardiac cycle due to systolic compression of the vessel as it is within the myocardium, rather than at the epicardium. This has important implications on the way pressure-based indices can be used to assess functional significance.

Studies measuring coronary pressure and flow velocity have demonstrated that there is limited or no flow through the MB segment in systole. ${ }^{77-79}$ This is followed by a spike in coronary flow in the early stages of diastole secondary to compensatory decreased microvascular resistance and concomitant residual myocardial compression. This increase in flow however, is not reflected in measured invasive pressure. The coronary pressure is highest during systole, and at times exceeds $\mathrm{Pa}$. This is due to the ventricularisation of coronary pressure secondary to myocardial compression. Given this, averaged whole-cycle pressure ratios such as FFR are unsuitable for the assessment of functional significance. ${ }^{77-79}$

In a study to address this, coronary assessment was performed using diastolic FFR (hyperaemic $\mathrm{Pd} / \mathrm{Pa}$ during diastole). ${ }^{80}$ This technique unmasked ischaemia in 5 of 12 patients, compared with conventional FFR, which demonstrated ischaemia in one patient. This led to speculations as to whether diastolic indices such as iFR would be more reliable in assessing the functional significance of MB. In another study, patients with angina or positive non-invasive test and $\mathrm{MB}$ underwent coronary assessment using FFR, iFR and hyperaemic WPR (HWPR; where iFR is measured during pharmacologically 
induced hyperaemia). Similar to diastolic FFR reported in the previous study, HWPR unmasked MB-related ischaemia in seven patients while FFR unmasked only one. After inotropic infusion-when most patients developed symptoms-HWPR dropped significantly while FFR did not. ${ }^{81}$ Other studies have demonstrated the importance of inotropic stimulation at unmasking ischaemia when assessing the functional significance of MBs. ${ }^{82}$

The use of NHPRs may therefore not be appropriate for assessing MB. The use of diastolic indices appears to be more appropriate than whole-cycle indices. Future studies may provide further insight on the use of hyperaemic diastolic indexes to assess MB.

\section{CONTROVERSIES IN THE USE OF NHPR}

The evolution of NHPR has polarised opinions within the field with some questioning whether NHPRs can fully account for the fundamental principles of coronary and microcirculatory physiology. ${ }^{83}$ In particular, it is debated whether a truly WFP exists with no fluctuations in the microcirculatory resistance. ${ }^{22} 8485$ These differences may be less relevant with the emergence of trials and subsequently guidelines supporting the use of iFR in clinical practice. The recent evidence demonstrating that iFR and other resting diastolic indices having a $>0.99$ correlation and AUC values has reignited the debate and led to the widely shared opinion that using proprietarysegmentation of the cardiac cycle offers no additive benefit. ${ }^{86}$ A recognised limitation of NHPRs is that they have been validated in cohorts of patients with intermediate coronary stenosis ${ }^{3578}$ and there is limited data examining the physiological validity of iFR in increasingly stenotic lesions. $^{87}$

A widely debated area remains the clinical relevance of discordance between the FFR and NHPR.27 374988 Most data on discordance currently exist on the comparison between iFR and FFR, with discordance believed to occur $\sim 15 \%-20 \%$ of lesions, particularly in those subtending large areas of myocardium, that is, LMCA and proximal LAD. ${ }^{49} 89$ Other areas where discordance has been identified include the pattern of coronary disease (focal vs diffuse),${ }^{90}$ and patient characteristics such as gender, presence of diabetes mellitus and beta blocker use. ${ }^{91-94} \mathrm{~A}$ summary of these discordant groups associated with FFR and iFR is presented in table 2.

The notion of discordance has created considerable discussion regarding the use of NHPRs in assessing lesions, particularly those in proximal coronary segments where they are most prognostically important. However, proponents of iFR have demonstrated that where discordance occurs, iFR better correlates with both thermodilutionderived and Doppler-derived CFR ${ }^{92}{ }^{95}$ Studies have also shown that increased risk of adverse outcomes only occurred when both iFR and FFR were both concordantly abnormal, and not in the discordant groups. ${ }^{92}{ }^{96}$ Unlike FFR however, ${ }^{97}$ long-term outcome data are not available for NHPRs and will likely be key in reassuring those with ongoing concerns.

\section{CONCLUSIONS}

The emergence of NHPRs has not been without controversy and their uptake has been marred by uncertainties within the interventional community. Nonetheless, there is a plethora of evidence supporting their use, particularly with iFR, which is now guideline-recommended on the basis of randomised clinical trial data. Other NHPRs have excellent correlations with iFR, suggesting they can be used interchangeably. Certain NHPRs may be better tailored to specific patient and clinical scenarios, although further evidence is required, as is long-term clinical data to support their use. What is clear is that increasing physiologically-guided revascularisation, whether by FFR or NHPR, must remain the goal to improve patient outcomes.

\section{Twitter Abdul Rahman Ihdayhid @Aihdayhid}

Contributors MM, conceptualisation, literature search and writing; UT, literature search and writing; JR, literature search and writing, $A C$, literature search and writing; $A R I$, literature search and writing; JDC, SN, SH AB, supervision, reviewing and editing.

Funding The authors have not declared a specific grant for this research from any funding agency in the public, commercial or not-for-profit sectors.

Competing interests ARI has received consulting fees from Boston Scientific and Canon Medical. SH has received speaker's bureau and proctoring fees from Abbott Vascular and Boston Scientific. AB has received consultancy fees from Abbott Vascular and Boston Scientific.

Patient consent for publication Not required.

Provenance and peer review Not commissioned; externally peer reviewed.

Data availability statement Data sharing not applicable as no datasets generated and/or analysed for this study.

Open access This is an open access article distributed in accordance with the Creative Commons Attribution Non Commercial (CC BY-NC 4.0) license, which permits others to distribute, remix, adapt, build upon this work non-commercially, and license their derivative works on different terms, provided the original work is properly cited, appropriate credit is given, any changes made indicated, and the use is non-commercial. See: http://creativecommons.org/licenses/by-nc/4.0/.

ORCID iD

Michael Michail http://orcid.org/0000-0001-5553-3144

\section{REFERENCES}

1 Roth GA, Johnson C, Abajobir A, et al. Global, regional, and national burden of cardiovascular diseases for 10 causes, 1990 to 2015 . J Am Coll Cardiol 2017;70:1-25.

2 Götberg M, Cook CM, Sen S, et al. The evolving future of instantaneous wave-free ratio and fractional flow reserve. J Am Coll Cardiol 2017;70:1379-402.

3 Davies JE, Sen S, Dehbi H-M, et al. Use of the instantaneous wave-free ratio or fractional flow reserve in $\mathrm{PCl}$. N Engl J Med 2017;376:1824-34.

4 Berry C, van 't Veer M, Witt N, et al. Verify (verification of instantaneous wave-free ratio and fractional flow reserve for the assessment of coronary artery stenosis severity in everyday practice): a multicenter study in consecutive patients. J Am Coll Cardiol 2013;61:1421-7.

5 Götberg M, Christiansen EH, Gudmundsdottir IJ, et al. Instantaneous wave-free ratio versus fractional flow reserve to guide $\mathrm{PCl}$. $N$ Engl J Med 2017;376:1813-23.

6 Neumann F-J, Sousa-Uva M, Ahlsson A, et al. 2018 ESC/ EACTS guidelines on myocardial revascularization. Eur Heart $J$ 2019;40:87-165. 
7 Svanerud J, Ahn J-M, Jeremias A, et al. Validation of a novel non-hyperaemic index of coronary artery stenosis severity: the resting full-cycle ratio (validate RFR) study. Eurolntervention 2018:14:806-14.

8 Johnson NP, Li W, Chen X, et al. Diastolic pressure ratio: new approach and validation vs. the instantaneous wave-free ratio. Eur Heart J 2019;40:2585-94.

9 Pijls NH, De Bruyne B, Peels K, et al. Measurement of fractional flow reserve to assess the functional severity of coronary-artery stenoses. N Engl J Med 1996;334:1703-8.

10 Bech GJ, Pijls NH, De Bruyne B, et al. Usefulness of fractional flow reserve to predict clinical outcome after balloon angioplasty. Circulation 1999;99:883-8.

11 Pijls NHJ, Klauss V, Siebert U, et al. Coronary pressure measurement after stenting predicts adverse events at follow-up: a multicenter registry. Circulation 2002;105:2950-4.

12 Tonino PAL, De Bruyne B, Piils NHJ, et al. Fractional flow reserve versus angiography for guiding percutaneous coronary intervention. N Engl J Med 2009;360:213-24.

13 Pijls NHJ, Fearon WF, Tonino PAL, et al. Fractional flow reserve versus angiography for guiding percutaneous coronary intervention in patients with multivessel coronary artery disease: 2-year followup of the fame (fractional flow reserve versus angiography for multivessel evaluation) study. J Am Coll Cardiol 2010;56:177-84.

14 Tonino PAL, Fearon WF, De Bruyne B, et al. Angiographic versus functional severity of coronary artery stenoses in the fame study fractional flow reserve versus angiography in multivessel evaluation. J Am Coll Cardiol 2010;55:2816-21.

15 Leesar MA, Satran A, Yalamanchili V, et al. The impact of fractional flow reserve measurement on clinical outcomes after transradial coronary stenting. Eurolntervention 2011;7:917-23.

16 De Bruyne B, Pijls NHJ, Kalesan B, et al. Fractional flow reserveguided $\mathrm{PCl}$ versus medical therapy in stable coronary disease. $N$ Engl J Med 2012;367:991-1001.

17 Hoffman JI, Spaan JA. Pressure-flow relations in coronary circulation. Physiol Rev 1990;70:331-90.

18 Spaan JA, Cornelissen AJ, Chan C, et al. Dynamics of flow, resistance, and intramural vascular volume in canine coronary circulation. Am J Physiol Heart Circ Physiol 2000;278:H383-403.

19 Davies JE, Whinnett ZI, Francis DP, et al. Evidence of a dominant backward-propagating "suction" wave responsible for diastolic coronary filling in humans, attenuated in left ventricular hypertrophy. Circulation 2006;113:1768-78.

20 Parker $\mathrm{KH}$, Jones CJ. Forward and backward running waves in the arteries: analysis using the method of characteristics. J Biomech Eng 1990;112:322-6.

21 Sen S, Escaned J, Malik IS, et al. Development and validation of a new adenosine-independent index of stenosis severity from coronary wave-intensity analysis: results of the advise (adenosine vasodilator independent stenosis evaluation) study. J Am Coll Cardiol 2012;59:1392-402.

22 Van't Veer M, Pijls NHJ, Hennigan B, et al. Comparison of different diastolic resting indexes to iFR: are they all equal? J Am Coll Cardiol 2017;70:3088-96.

23 Ligthart J, Masdjedi K, Witberg K, et al. Validation of resting diastolic pressure ratio calculated by a novel algorithm and its correlation with distal coronary artery pressure to aortic pressure, instantaneous wave-free ratio, and fractional flow reserve. Circ Cardiovasc Interv 2018:11:e006911.

24 Lee JM, Choi KH, Park J, et al. Physiological and clinical assessment of resting physiological indexes. Circulation 2019;139:889-900.

25 Casadonte L, Verhoeff B-J, Piek JJ, et al. Influence of increased heart rate and aortic pressure on resting indices of functional coronary stenosis severity. Basic Res Cardiol 2017;112:61.

26 Johnson NP, Tóth GG, Lai D, et al. Prognostic value of fractional flow reserve: linking physiologic severity to clinical outcomes. J Am Coll Cardiol 2014:64:1641-54

27 Jeremias A, Maehara A, Généreux P, et al. Multicenter core laboratory comparison of the instantaneous wave-free ratio and resting $\mathrm{Pd} / \mathrm{Pa}$ with fractional flow reserve: the resolve study. J Am Coll Cardiol 2014;63:1253-61.

28 Escaned J, Echavarría-Pinto M, Garcia-Garcia HM, et al. Prospective assessment of the diagnostic accuracy of instantaneous wave-free ratio to assess coronary stenosis relevance: results of advise II international, multicenter study (adenosine vasodilator independent stenosis evaluation II). JACC Cardiovasc Interv 2015;8:824-33.

29 Park JJ, Petraco R, Nam C-W, et al. Clinical validation of the resting pressure parameters in the assessment of functionally significant coronary stenosis; results of an independent, blinded comparison with fractional flow reserve. Int J Cardiol 2013;168:4070-5.
30 Petraco R, van de Hoef TP, Nijjer S, et al. Baseline instantaneous wave-free ratio as a pressure-only estimation of underlying coronary flow reserve: results of the JUSTIFY-CFR study (joined coronary pressure and flow analysis to determine diagnostic characteristics of basal and hyperemic indices of functional lesion Severity-Coronary flow reserve). Circ Cardiovasc Interv 2014;7:492-502.

31 Hennigan B, Oldroyd KG, Berry C, et al. Discordance between resting and hyperemic indices of coronary stenosis severity: the verify 2 study (a comparative study of resting coronary pressure gradient, instantaneous wave-free ratio and fractional flow reserve in an unselected population referred for invasive angiography). Circ Cardiovasc Interv 2016;9:e004016.

32 Sen S, Ahmad Y, Dehbi H-M, et al. Clinical events after deferral of LAD revascularization following physiological coronary assessment. J Am Coll Cardiol 2019;73:444-53.

33 Kumar G, Desai R, Gore A, et al. Real world validation of the nonhyperemic index of coronary artery stenosis severity-resting full-cycle ratio-RE-VALIDATE. Catheter Cardiovasc Interv 2019.

34 Marcus JT, Smeenk HG, Kuijer JP, et al. Flow profiles in the left anterior descending and the right coronary artery assessed by $\mathrm{Mr}$ velocity quantification: effects of through-plane and in-plane motion of the heart. J Comput Assist Tomogr 1999;23:567-76.

35 Hadjiloizou N, Davies JE, Malik IS, et al. Differences in cardiac microcirculatory wave patterns between the proximal left mainstem and proximal right coronary artery. Am J Physiol Heart Circ Physiol 2008;295:H1198-205.

36 Gore A, Ahn J-M, Veer Marcel van 't, et al. TCT-154 diagnostic accuracy of iFR versus FFR in the left versus right coronary artery. $J$ Am Coll Cardiol 2018;72:B66.

37 Michail M, Ihdayhid AR, Brown AJ, et al. Discordance of intracoronary pressure-based indices in severe angiographic stenosis: are we missing the flow? Cardiovasc Interv Ther 2020;35:304-5.

38 Maini R, Moscona J, Sidhu G, et al. Pooled diagnostic accuracy of resting distal to aortic coronary pressure referenced to fractional flow reserve: the importance of resting coronary physiology. $J$ Interv Cardiol 2018;31:588-98

39 Lee JM, Park J, Hwang D, et al. Similarity and difference of resting distal to aortic coronary pressure and instantaneous wave-free ratio. J Am Coll Cardiol 2017;70:2114-23.

$40 \mathrm{Kim} \mathrm{H-L,} \mathrm{Koo} \mathrm{B-K,} \mathrm{Nam} \mathrm{C-W,} \mathrm{et} \mathrm{al.} \mathrm{Clinical} \mathrm{and} \mathrm{physiological}$ outcomes of fractional flow reserve-guided percutaneous coronary intervention in patients with serial stenoses within one coronary artery. JACC Cardiovasc Interv 2012;5:1013-8.

41 Gould KL, Lipscomb K, Hamilton GW. Physiologic basis for assessing critical coronary stenosis. instantaneous flow response and regional distribution during coronary hyperemia as measures of coronary flow reserve. Am J Cardiol 1974;33:87-94.

42 Nijier SS, Sen S, Petraco R, et al. The instantaneous wave-free ratio (iFR) pullback: a novel innovation using baseline physiology to optimise coronary angioplasty in tandem lesions. Cardiovasc Revasc Med 2015;16:167-71.

43 Nijjer SS, Sen S, Petraco R, et al. Pre-angioplasty instantaneous wave-free ratio pullback provides virtual intervention and predicts hemodynamic outcome for serial lesions and diffuse coronary artery disease. JACC Cardiovasc Interv 2014;7:1386-96.

44 Kikuta Y, Cook CM, Sharp ASP, et al. Pre-angioplasty instantaneous wave-free ratio Pullback predicts hemodynamic outcome In humans with coronary artery disease: primary results of the International multicenter iFR gradient registry.. JACC Cardiovasc Interv 2018;11:757-67.

45 Jeremias A, Davies JE, Maehara A, et al. Blinded physiological assessment of residual ischemia after successful angiographic percutaneous coronary The DEFINE PCI Study. JACC CardiovasC Interv 2019:12:1991-2001.

46 Agarwal SK, Kasula S, Hacioglu Y, et al. Utilizing post-intervention fractional flow reserve to optimize acute results and the relationship to long-term outcomes. JACC Cardiovasc Interv 2016;9:1022-31.

47 Lindstaedt M, Spiecker M, Perings C, et al. How good are experienced interventional cardiologists at predicting the functional significance of intermediate or equivocal left main coronary artery stenoses? Int J Cardiol 2007;120:254-61.

48 Mallidi J, Atreya AR, Cook J, et al. Long-term outcomes following fractional flow reserve-guided treatment of angiographically ambiguous left main coronary artery disease: a meta-analysis of prospective cohort studies. Catheter Cardiovasc Interv 2015;86:12-18

49 Kobayashi Y, Johnson NP, Berry C, et al. The influence of lesion location on the diagnostic accuracy of Adenosine-Free coronary pressure wire measurements. JACC Cardiovasc Interv 2016:9:2390-9. 
50 De Rosa S, Polimeni A, De Velli G, et al. Reliability of instantaneous wave-free ratio (iFR) for the evaluation of left main coronary artery lesions. J Clin Med 2019;8. doi:10.3390/jcm8081143. [Epub ahead of print: 31 Jul 2019].

51 Ihdayhid AR, Koh J-S, Ramzy J, et al. The role of fractional flow reserve and instantaneous wave-free ratio measurements in patients with acute coronary syndrome. Curr Cardiol Rep 2019;21:159.

52 Halkin A, Singh M, Nikolsky E, et al. Prediction of mortality after primary percutaneous coronary intervention for acute myocardial infarction: the CADILLAC risk score. J Am Coll Cardiol 2005;45:1397-405.

53 Sorajja P, Gersh BJ, Cox DA, et al. Impact of multivessel disease on reperfusion success and clinical outcomes in patients undergoing primary percutaneous coronary intervention for acute myocardial infarction. Eur Heart J 2007;28:1709-16.

54 van der Hoeven NW, Janssens GN, de Waard GA, et al. Temporal changes in coronary hyperemic and resting hemodynamic indices in Nonculprit vessels of patients with ST-segment elevation myocardial infarction. JAMA Cardiol 2019;4:736.

55 Ntalianis A, Sels J-W, Davidavicius G, et al. Fractional flow reserve for the assessment of nonculprit coronary artery stenoses in patients with acute myocardial infarction. JACC Cardiovasc Interv 2010;3:1274-81.

56 Lee JM, Kim HK, Lim KS, et al. Influence of local myocardial damage on index of microcirculatory resistance and fractional flow reserve in target and nontarget vascular territories in a porcine microvascular injury model. JACC Cardiovasc Interv 2018;11:717-24.

57 Engstrøm T, Kelbæk H, Helqvist S, et al. Complete revascularisation versus treatment of the culprit lesion only in patients with STsegment elevation myocardial infarction and multivessel disease (DANAMI-3-PRIMULTI): an open-label, randomised controlled trial. Lancet 2015;386:665-71.

58 Smits PC, Abdel-Wahab M, Neumann F-J, et al. Fractional flow reserve-guided multivessel angioplasty in myocardial infarction. $N$ Engl J Med 2017;376:1234-44.

59 Choi KH, Lee JM, Kim HK, et al. Fractional flow reserve and instantaneous wave-free ratio for Nonculprit stenosis in patients with acute myocardial infarction. JACC Cardiovasc Interv 2018;11:1848-58.

60 de Waard GA, Hollander MR, Teunissen PFA, et al. Changes in coronary blood flow after acute myocardial infarction: insights from a patient study and an experimental porcine model. JACC Cardiovasc Interv 2016;9:602-13.

61 Mejía-Rentería H, Lee JM, van der Hoeven NW, et al. Coronary microcirculation downstream Non-Infarct-Related arteries in the subacute phase of myocardial infarction: implications for PhysiologyGuided revascularization. J Am Heart Assoc 2019;8:e011534.

62 Ely SW, Berne RM. Protective effects of adenosine in myocardial ischemia. Circulation 1992;85:893-904.

63 Thim T, Götberg M, Fröbert O, et al. Nonculprit stenosis evaluation using instantaneous wave-free ratio in patients with ST-segment elevation myocardial infarction. JACC Cardiovasc Interv 2017;10:2528-35.

64 Escaned J, Ryan N, Mejía-Rentería H, et al. Safety of the deferral of coronary revascularization on the basis of instantaneous wave-free ratio and fractional flow reserve measurements in stable coronary artery disease and acute coronary syndromes. JACC CardiovasC Interv 2018;11:1437-49.

65 Witberg G, Zusman O, Codner P, et al. Impact of coronary artery revascularization completeness on outcomes of patients with coronary artery disease undergoing transcatheter aortic valve replacement: a meta-analysis of studies using the residual SYNTAX score (synergy between $\mathrm{PCl}$ with Taxus and cardiac surgery). Circ Cardiovasc Interv 2018;11:e006000.

66 Michail M, Davies JE, Cameron JD, et al. Pathophysiological coronary and microcirculatory flow alterations in aortic stenosis. Nat Rev Cardiol 2018;15:420-31.

67 Wiegerinck EMA, van de Hoef TP, Rolandi MC, et al. Impact of aortic valve stenosis on coronary hemodynamics and the instantaneous effect of transcatheter aortic valve implantation. Circ Cardiovasc Interv 2015;8:e002443.

68 Rolandi MC, Wiegerinck EMA, Casadonte L, et al. Transcatheter replacement of stenotic aortic valve normalizes Cardiac-Coronary interaction by restoration of systolic coronary flow dynamics as assessed by wave intensity analysis. Circ Cardiovasc Interv 2016;9:e002356.

69 Rajappan K, Rimoldi OE, Dutka DP, et al. Mechanisms of coronary microcirculatory dysfunction in patients with aortic stenosis and angiographically normal coronary arteries. Circulation 2002;105:470-6.
70 Scarsini R, Pesarini G, Zivelonghi C, et al. Physiologic evaluation of coronary lesions using instantaneous wave-free ratio (iFR) in patients with severe aortic stenosis undergoing transcatheter aortic valve implantation. Eurolntervention 2018;13:1512-9.

71 Ahmad Y, Götberg M, Cook C, et al. Coronary hemodynamics in patients with severe aortic stenosis and coronary artery disease undergoing transcatheter aortic valve replacement: implications for clinical indices of coronary stenosis severity. JACC Cardiovasc Interv 2018;11:2019-31.

72 Yamanaka F, Shishido K, Ochiai T, et al. Instantaneous wavefree ratio for the assessment of intermediate coronary artery stenosis in patients with severe aortic valve stenosis: comparison with myocardial perfusion Scintigraphy. JACC Cardiovasc Interv 2018;11:2032-40.

73 Pesarini G, Scarsini R, Zivelonghi C, et al. Functional assessment of coronary artery disease in patients undergoing transcatheter aortic valve implantation: influence of pressure overload on the evaluation of lesions severity. Circ Cardiovasc Interv 2016;9.

74 Tauth J, Sullebarger T. Myocardial infarction associated with myocardial bridging: case history and review of the literature. Cathet Cardiovasc Diagn 1997;40:364-7.

75 Migliore F, Maffei E, Perazzolo Marra M, et al. LAD coronary artery myocardial bridging and apical ballooning syndrome. JACC Cardiovasc Imaging 2013;6:32-41.

76 Feld H, Guadanino V, Hollander G, et al. Exercise-induced ventricular tachycardia in association with a myocardial bridge. Chest 1991;99:1295-6.

77 Corban MT, Hung OY, Eshtehardi P, et al. Myocardial bridging: contemporary understanding of pathophysiology with implications for diagnostic and therapeutic strategies. J Am Coll Cardiol 2014;63:2346-55.

78 Schwarz ER, Klues HG, vom Dahl J, et al. Functional, angiographic and intracoronary doppler flow characteristics in symptomatic patients with myocardial bridging: effect of short-term intravenous beta-blocker medication. J Am Coll Cardiol 1996;27:1637-45.

79 Schwarz ER, Klues HG, vom Dahl J, et al. Functional characteristics of myocardial bridging. a combined angiographic and intracoronary Doppler flow study. Eur Heart J 1997;18:434-42.

80 Escaned J, Cortés J, Flores A, et al. Importance of diastolic fractiona flow reserve and dobutamine challenge in physiologic assessment of myocardial bridging. J Am Coll Cardiol 2003;42:226-33.

81 Tarantini G, Barioli A, Nai Fovino L, et al. Unmasking myocardial bridge-related ischemia by intracoronary functional evaluation. Circ Cardiovasc Interv 2018;11:e006247.

82 Hakeem A, Cilingiroglu M, Leesar MA. Hemodynamic and intravascular ultrasound assessment of myocardial bridging: fractional flow reserve paradox with dobutamine versus adenosine. Catheter Cardiovasc Interv 2010;75:229-36.

83 Pijls NHJ, Van 't Veer M, Oldroyd KG, et al. Instantaneous wavefree ratio or fractional flow reserve without hyperemia: novelty or nonsense? J Am Coll Cardiol 2012;59:1916-7.

84 Westerhof N, Segers P, Westerhof BE, et al. Wave separation, wave intensity, the Reservoir-Wave concept, and the instantaneous Wave-Free ratio: presumptions and principles. Hypertension 2015;66:93-8.

85 Johnson NP, Kirkeeide RL, Asrress KN, et al. Does the instantaneous wave-free ratio approximate the fractional flow reserve? J Am Coll Cardiol 2013;61:1428-35.

86 Gould KL, Johnson NP, Kirkeeide RL. Approximate truth. J Am Coll Cardiol 2017;70:3097-101.

87 Lee JM, Hwang D, Park J, et al. Exploring coronary circulatory response to stenosis and its association with invasive physiologic indexes using absolute myocardial blood flow and coronary pressure. Circulation 2017;136:1798-808.

88 Indayhid AR, Seneviratne SK, Cameron J, et al. Resting indexes in the functional assessment of left main and left anterior descending coronary stenoses: a case for caution. JACC Cardiovasc Interv 2018;11:1531-3

89 Hennigan B, Oldroyd KG, Berry C, et al. Discordance between resting and hyperemic indices of coronary stenosis severity: the verify 2 study (a comparative study of resting coronary pressure gradient, instantaneous wave-free ratio and fractional flow reserve in an unselected population referred for invasive angiography). Circ Cardiovasc Interv 2016;9.

90 Warisawa T, Cook CM, Howard JP, et al. Physiological pattern of disease assessed by pressure-wire pullback has an influence on fractional flow reserve/instantaneous wave-free ratio discordance. Circ Cardiovasc Interv 2019;12:e007494.

91 Lee JM, Shin E-S, Nam C-W, et al. Discrepancy between fractional flow reserve and instantaneous wave-free ratio: clinical and angiographic characteristics. Int J Cardiol 2017;245:63-8. 
92 Lee SH, Choi KH, Lee JM, et al. Physiologic characteristics and clinical outcomes of patients with discordance between FFR and iFR. JACC Cardiovasc Interv 2019;12:2018-31.

93 Arashi H, Satomi N, Ishida I, et al. Hemodynamic and lesion characteristics associated with discordance between the instantaneous wave-free ratio and fractional flow reserve. J Interv Cardiol 2019;2019:1-8.

94 Dérimay F, Johnson NP, Zimmermann FM, et al. Predictive factors of discordance between the instantaneous wave-free ratio and fractional flow reserve. Catheter Cardiovasc Interv 2019;94:356-63.

95 Cook CM, Jeremias A, Petraco R, et al. Fractional flow reserve/ instantaneous wave-free ratio discordance in angiographically intermediate coronary stenoses: an analysis using Dopplerderived coronary flow measurements. JACC Cardiovasc Interv 2017; 10:2514-24.

96 Lee JM, Shin E-S, Nam C-W, et al. Clinical outcomes according to fractional flow reserve or instantaneous wave-free ratio indeferred lesions. JACC Cardiovasc Interv 2017;10:2502-10.

97 Xaplanteris P, Fournier S, Pijls NHJ, et al. Five-year outcomes with $\mathrm{PCl}$ guided by fractional flow reserve. N Engl J Med 2018;379:250-9.

98 Johnson NP, Jeremias A, Zimmermann FM, et al. Continuum of vasodilator stress from rest to contrast medium to adenosine hyperemia for fractional flow reserve assessment. JACC Cardiovasc Interv 2016;9:757-67. 